\title{
Network meta-analysis of the efalysis Network meta-analysis of the efficacy of first-line chemotherapy regimens in patients with advanced colorectal cancer
}

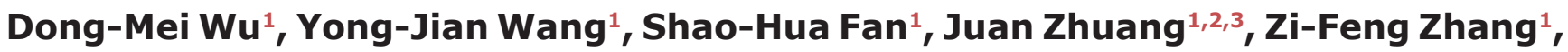 \\ Qun Shan ${ }^{1}$, Xin-Rui Han ${ }^{1}$, Xin Wen ${ }^{1}$, Meng-Qiu Li ${ }^{1}$, Bin Hu${ }^{1}$, Chun-Hui Sun ${ }^{1}$, Ya-Xing \\ Bao $^{4}$, Hai-Juan Xiao5, Lin Yang ${ }^{6}$, Jun Lu' ${ }^{1}$ and Yuan-Lin Zheng ${ }^{1}$ \\ ${ }^{1}$ Key Laboratory for Biotechnology on Medicinal Plants of Jiangsu Province, School of Life Science, Jiangsu Normal University, \\ Xuzhou 221116, P.R. China \\ ${ }^{2}$ School of Environment Science and Spatial Informatics, China University of Mining and Technology, Xuzhou 221008, P.R. \\ China \\ ${ }^{3}$ Jiangsu Key Laboratory for Eco-Agricultural Biotechnology around Hongze Lake, School of Life Sciences, Huaiyin Normal \\ University, Huaian 223300, P.R. China \\ ${ }^{4}$ Department of Orthopaedics, The Affiliated Municipal Hospital of Xuzhou Medical University, Xuzhou 221009, P.R. China \\ ${ }^{5}$ Department of Oncology, Hospital Affiliated to Shaanxi University of Chinese Medicine, Xianyang 712000, P.R. China \\ ${ }^{6}$ Department of Hepatobiliary Surgery, Xianyang Central Hospital, Xianyang 712000, P.R. China \\ Correspondence to: Jun Lu, email: Iu-jun75@163.com \\ Yuan-Lin Zheng, email: ylzheng@jsnu.edu.cn
}

Keywords: advanced colorectal cancer; chemotherapy; efficacy; randomized controlled trial; bayesian network model

Received: February 21, $2017 \quad$ Accepted: October 13,2017 Published: October 31, 2017

Copyright: Wu et al. This is an open-access article distributed under the terms of the Creative Commons Attribution License 3.0 (CC BY 3.0), which permits unrestricted use, distribution, and reproduction in any medium, provided the original author and source are credited.

\section{ABSTRACT}

This network meta-analysis compared the short-term and long-term efficacies of first-line chemotherapy regimens in patients with advanced colorectal cancer (CRC). The 10 regimens included folinic acid + 5-fluorouracil + oxaliplatin (FOLFOX), folinic acid + 5-fluorouracil + irinotecan (FOLFIRI), folinic acid + 5-fluorouracil + gemcitabine (FFG), folinic acid + 5-fluorouracil + trimetrexate (FFT), folinic acid + 5-fluorouracil (FF), irinotecan + oxaliplatin (IROX), raltitrexed + oxaliplatin (TOMOX), folinic acid + tegafur-uracil (FTU), raltitrexed, and capecitabine. Electronic searches were performed in the Cochrane Library, PubMed and Embase databases from inception to June 2017. Network meta-analysis combined direct and indirect evidence to obtain odds ratios (ORs) and surface under the cumulative ranking curves (SUCRA) of different chemotherapy regimens for advanced CRC. Fourteen randomized controlled trails (RCTs) covering 4,383 patients with advanced CRC were included. The results revealed that FOLFOX, FOLFIRI, IROX, and TOMOX all showed higher overall response rates (ORRs) than FF or raltitrexed. Compared with raltitrexed, the aforementioned four regimens also had higher 1-year progressionfree survival (PFS) rates. In addition, FOLFOX and FOLFIRI exhibited higher disease control rates (DCRs) and 1-year PFS rates than FF or raltitrexed. Cluster analysis revealed that FOLFOX, FOLFIRI, and TOMOX had better short-term and long-term efficacies. These findings suggest FOLFOX, FOLFIRI, and TOMOX are superior to other regimens for advanced CRC. These three regimens are therefore recommended for clinical treatment of advanced CRC. 


\section{INTRODUCTION}

Colorectal cancer (CRC) is the most commonly diagnosed cancer and is the fourth leading cause of cancer-related deaths all over the world $[1,2]$. According to the World Health Organization (WHO) estimates for 2030, CRC new cases will increase by $77 \%$ annually and CRC-related deaths will increase by $80 \%$ [3]. CRC results from benign neoplasms, such as tubular adenomas and serrated polyps, which evolve into CRC over many years and undergo malignant transformation [4]. CRC is preventable with early diagnosis, and currently, medical imaging is an important modality for screening, staging, and surveillance of CRC [5]. The most often treatments of CRC can be surgical resection, adjuvant chemotherapy, and drug therapy [1]. Because of the complex structure of the pelvis, the treatment of CRC is not completed by the surgical operation, so drug-combination chemotherapy has also become a common treatment of CRC [6].

Drug chemotherapy can inhibit the proliferation of tumor cells when the chemical compounds are directed at the signal pathways in tumor cells [7]. Although 5 -fluorourcacil (5-FU) is widely used in the treatment of CRC, drug resistance limits its clinical application [8], which means that 5-FU alone has low efficacy in the treatment of CRC [9]. Studies indicate that regimens containing cytotoxic drugs such as raltitrexed, oxaliplatin, and irinotecan could improve patient outcomes $[10,11]$. Consequently, researchers have developed important insight into combining various compounds to improve therapeutic efficacy and reduce the side effects of drugs [12]. A study demonstrated that when associated with folinic acid, 5-FU enhances the clinical response, and when combined with irinotecan or oxaliplatin, 5-FU increases survival rates in CRC patients [13]. When 5 -FU is combined with either agent, response rates (RRs) increase from $15 \%-25 \%$ to $40 \%-50 \%$, and overall survival (OS) is prolonged to more than 20 months. When three active agents such as 5-FU, irinotecan, and oxaliplatin are combined in one regimen, the combination shows only partly overlapping toxicity profiles, which means that a triple combination might be feasible [14]. However, the combination of various drugs has not achieved significant improvement [15], suggesting that the most effective therapeutic regimen for the treatment and management of CRC remains to be determined.

A network meta-analysis can summarize all included research results, and then an integrated analysis of intervention experiments can be performed to establish a net-like relation to analyze efficiencies of multiple interventions in the disease and to screen for valuable results [16]. It is well known that the targeted drug is really a feasible and efficient assisted strategy and chemotherapeutic drugs exhibit many varieties and some relevant researches increasingly updated [17], Wondering whether there exist chances of the combination of various chemotherapeutic drugs and with the aim of producing more reliable guidance for the drug regimens for advanced CRC, we thus perform a network meta-analysis to compare the short-term and long-term efficacies of different first-line chemotherapy regimens in the treatment of advanced CRC.

\section{RESULTS}

\section{Baseline characteristics of included studies}

Through electronic and manual searches, 7,514 articles were found. After the initial screening, we excluded 2,913 duplicated articles, 722 letters or summaries, 598 articles on non-human studies, and 681 non-English articles. For the remaining 2,600 articles, after detailed assessment of the full text, we excluded 631 articles on targeted therapy, 1,211 articles that were irrelevant with the advanced CRC, 743 articles that were irrelevant with chemotherapy, and 1 article with no data or insufficient data. Eventually, 14 eligible randomized control trials (RCTs) which were published between 1996 and 2015 were included for this network meta-analysis (Figure 1) [18-31]. All these studies objects were from European and American populations and the 14 studies were part of two-arm trials. The baseline characteristics of included studies are shown in Table 1, and the PEDro scale for literature quality assessment is displayed in Supplementary Figure 1.

\section{Pairwise meta-analysis of ORR, DCR, 1-year OS rate, 2-year OS rate, 1-year PFS rate, and 2-year PFS rate for patients with advanced CRC}

The direct paired comparisons were performed for the short-term and long-term efficacies of 10 first-line chemotherapy regimens in the treatment of advanced $\mathrm{CRC}$, and the results indicated that for ORR, DCR, and 1-year PFS rate, the efficacy of FF was poor compared with FOLFOX $(\mathrm{OR}=2.97,95 \% \mathrm{CI}=2.14-4.14$; $\mathrm{OR}=1.91,95 \% \mathrm{CI}=1.34-2.71 ; \mathrm{OR}=2.34,95 \%$ $\mathrm{CI}=1.61-3.41$, respectively) (Supplementary Table 1). However, in terms of 1-year OS rate, 2-year OS rate, and 2 -year PFS rate, there was no significant difference in the results. Overall, the efficacy of FOLFOX chemotherapy was much better, while FF chemotherapy regimen was poor for patients with advanced CRC.

Evidence network of ORR, DCR, 1-year OS rate, 2-year OS rate, 3-year OS rate, 1-year PFS rate, and 2-year PFS rate for patients with advanced CRC

This study included 10 first-line chemotherapy regimens: FOLFOX, FOLFIRI, FFG, FFT, FF, IROX, TOMOX, FTU, raltitrexed, and capecitabine. More 
advanced CRC patients were treated with FOLFOX, FOLFIRI, and FF first-line chemotherapy regimens. In addition, more studies compared FOLFOX with FOLFIRI, FOLFOX with FF, and FF with raltitrexed (Figure 2).

Inconsistency test of ORR, DCR, 1-year OS rate, 2-year OS rate, 3-year OS rate, 1-year PFS rate, and 2-year PFS rate for patients with advanced CRC

The node-splitting method was used for the inconsistency test of ORR, DCR, 1-year OS rate, 2-year OS rate, and 1-year PFS rate, and the results demonstrated that all direct evidence and indirect evidence were consistent, suggesting the consistency model should be adopted (all $P>0.05$ ) (Table 2 ).

\section{Network meta-analysis of ORR, DCR, 1-year OS rate, 2-year OS rate, 3-year OS rate, 1-year PFS rate, and 2-year PFS rate for patients with advanced CRC}

As shown in Supplementary Table 2, network meta-analysis results revealed that FOLFOX, FOLFIRI, IROX, and TOMOX had better efficacies for patients with advanced CRC. The ORRs of these four chemotherapy regimens were higher than the ORR of FF $(\mathrm{OR}=2.95$,
$95 \% \mathrm{CI}=1.95-4.65 ; \mathrm{OR}=3.11,95 \% \mathrm{CI}=1.81-5.32$; $\mathrm{OR}=3.14,95 \% \mathrm{CI}=1.61-6.33$; and $\mathrm{OR}=4.36,95 \%$ $\mathrm{CI}=1.94-10.49$, respectively $)$ and raltitrexed $(\mathrm{OR}=2.78$, $95 \% \mathrm{CI}=1.58-5.02 ; \mathrm{OR}=2.93,95 \% \mathrm{CI}=1.54-5.47$; $\mathrm{OR}=2.92,95 \% \mathrm{CI}=1.47-5.89 ;$ and $\mathrm{OR}=4.13,95 \%$ $\mathrm{CI}=1.66-10.22$, respectively). Compared with raltitrexed, 1 -year PFS rates of FOLFOX, FOLFIRI, IROX, and TOMOX were higher $(\mathrm{OR}=3.66,95 \% \mathrm{CI}=1.62-9.74$; $\mathrm{OR}=3.26,95 \% \mathrm{CI}=1.34-10.09 ; \mathrm{OR}=3.02,95 \%$ $\mathrm{CI}=1.24-11.41$; and $\mathrm{OR}=3.76,95 \% \mathrm{CI}=1.04-16.72$, respectively). In addition, compared with raltitrexed, the DCR was higher in FOLFOX and FOLFIRI $(\mathrm{OR}=2.11,95 \% \mathrm{CI}=1.02-5.18$ and $\mathrm{OR}=2.59,95 \%$ $\mathrm{CI}=1.18-6.60$, respectively). Compared with FF, 1 -year PFS rate was higher in FOLFOX and FOLFIRI $(\mathrm{OR}=2.59,95 \% \mathrm{CI}=1.36-5.36$ and $\mathrm{OR}=2.36,95 \%$ $\mathrm{CI}=1.08-5.80$, respectively). It can be concluded that the efficacy of FOLFOX, FOLFIRI, IROX, and TOMOX were much better for patients with advanced CRC.

SUCRA of ORR, DCR, 1-year OS rate, 2-year OS rate, 3-year OS rate, 1-year PFS rate, and 2-year PFS rate for patients with advanced CRC

As shown in Table 3, the highest SUCRA values for ORR, DCR, 1-year OS rate, and 2-year OS rate (ORR: 91.8\%, DCR: $88.3 \%$, 1-year OS rate: $78.1 \%$, and 2-year

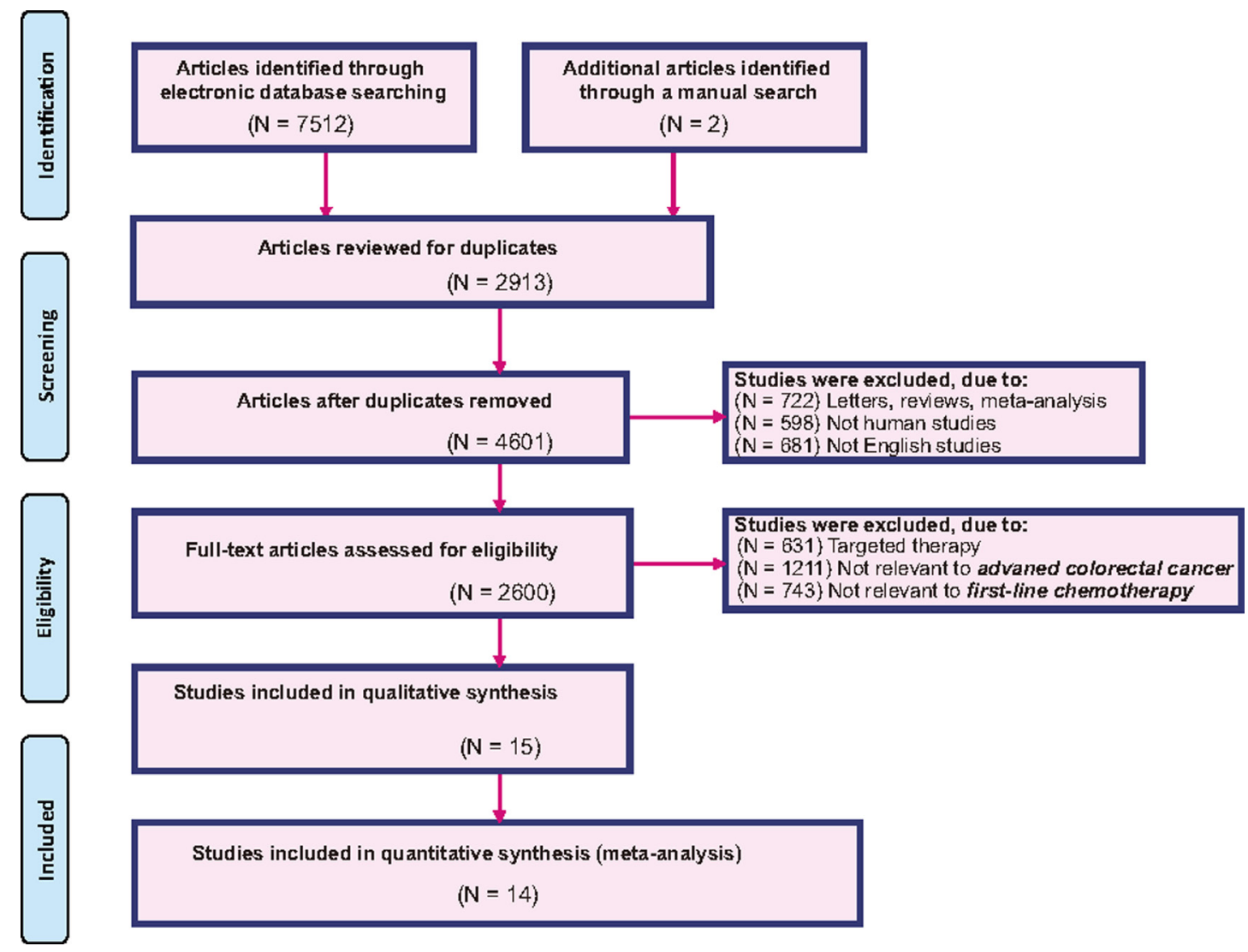

Figure 1: Flowchart of the literature search and screening results. 
Table 1: The baseline characteristics for included studies

\begin{tabular}{|c|c|c|c|c|c|c|c|c|c|c|c|c|}
\hline \multirow{2}{*}{ First author } & \multirow{2}{*}{ Year } & \multirow{2}{*}{ Country } & \multirow{2}{*}{ Phase } & \multicolumn{2}{|c|}{ Interventions } & \multirow{2}{*}{ Total } & \multicolumn{2}{|c|}{ Sample size } & \multicolumn{2}{|c|}{ Gender (M/F) } & \multicolumn{2}{|c|}{ Age (years) } \\
\hline & & & & T1 & $\mathbf{T} 2$ & & T1 & $\mathbf{T 2}$ & T1 & $\mathbf{T} 2$ & T1 & $\mathbf{T} 2$ \\
\hline Kroep JR & 2015 & The Netherlands & Phase III & $\mathrm{H}$ & $\mathrm{J}$ & 67 & 34 & 33 & $19 / 15$ & $17 / 16$ & $77(66-88)$ & $76(66-88)$ \\
\hline Madajewicz S & 2012 & America & Phase II & $\mathrm{A}$ & $\mathrm{C}$ & 48 & 24 & 24 & $9 / 15$ & $10 / 14$ & $64(32-81)$ & $63(28-79)$ \\
\hline Gravalos C & 2012 & Spain & Phase II & $\mathrm{A}$ & G & 183 & 91 & 92 & $48 / 43$ & $56 / 36$ & $61(35-82)$ & $65(36-78)$ \\
\hline Fischer von WL & 2011 & Germany & Phase III & $\mathrm{B}$ & $\mathrm{F}$ & 479 & 238 & 241 & $158 / 80$ & $177 / 64$ & $63(32-79)$ & $63(21-79)$ \\
\hline Hospers GA & 2006 & The Netherlands & Phase III & A & $\mathrm{E}$ & 302 & 151 & 151 & $100 / 51$ & $88 / 63$ & $62(41-80)$ & $62(28-84)$ \\
\hline Kalofonos HP & 2005 & Greece & Phase II & A & $\mathrm{B}$ & 295 & 148 & 147 & $92 / 56$ & $90 / 57$ & $65(28-78)$ & $66(28-78)$ \\
\hline Colucci G & 2005 & Italy & Phase III & A & B & 360 & 182 & 178 & $109 / 73$ & $93 / 85$ & $62(31-75)$ & $62(32-75)$ \\
\hline Tournigand C & 2004 & France & Phase III & A & B & 220 & 111 & 109 & $80 / 31$ & $62 / 47$ & $65(40-75)$ & $61(29-75)$ \\
\hline Scheithauer W & 2002 & Austria & Phase II & $\mathrm{F}$ & I & 92 & 46 & 46 & $27 / 19$ & $22 / 24$ & $65(38-75)$ & $68(31-75)$ \\
\hline Blanke CD & 2002 & Portland & Phase III & $\mathrm{D}$ & $\mathrm{E}$ & 382 & 191 & 191 & $61 / 39$ & $64 / 36$ & $66(22-86)$ & $63(25-90)$ \\
\hline Twelves C & 2001 & England & Phase III & $\mathrm{E}$ & $\mathrm{J}$ & 602 & 301 & 301 & $173 / 128$ & $172 / 129$ & $63.5(36-86)$ & $62(29-84)$ \\
\hline de Gramont A & 2000 & France & Phase III & A & $\mathrm{E}$ & 420 & 210 & 210 & $127 / 83$ & $122 / 88$ & $63(20-76)$ & $63(22-76)$ \\
\hline Cocconi G & 1998 & Italy & Phase II & $\mathrm{E}$ & I & 495 & 248 & 247 & $164 / 84$ & $152 / 95$ & $62(36-83)$ & $60(23-79)$ \\
\hline Cunningham D & 1996 & England & Phase III & $\mathrm{E}$ & I & 439 & 216 & 223 & $127 / 89$ & $133 / 90$ & $61(27-80)$ & $61(27-82)$ \\
\hline
\end{tabular}

Note: $\mathrm{T}=$ treatment $\mathrm{M}=$ male $\mathrm{F}=$ female $\mathrm{A}=\mathrm{FOLFOX}($ folinic acid +5 -fluorouracil + oxaliplatin $) ; \mathrm{B}=\mathrm{FOLFIRI}($ folinic acid +5 -fluorouracil + irinotecan $) ; \mathrm{C}=\mathrm{FFG}($ folinic acid + 5-fluorouracil + gemcitabine); D = FFT (folinic acid + 5-fluorouracil+trimetrexate); E = FF (folinic acid + 5-fluorouracil); F = IROX (irinotecan + oxaliplatin);

$\mathrm{G}=$ TOMOX (raltitrexed + oxaliplatin); H = FTU (folinic acid + tegafur-uracil); $\mathrm{I}=$ raltitrexed; $\mathrm{J}$ = capecitabine.

OS rate: $90.3 \%$, respectively) were found in TOMOX. For 1-year PFS rate and 2-year PFS rate, FOLFOX had the highest SUCRA values (1-year PFS rate: $84.4 \%$ and 2-year PFS rate: $76.0 \%$ ). For 3-year OS rate, FOLFIRI achieved the highest SUCRA value (81.0\%). Overall, FOLFOX, FOLFIRI, and TOMOX regimens were more effective in the treatment of patients with advanced CRC.

\section{Cluster analysis of ORR, DCR, 1-year OS rate, 2-year OS rate, 3-year OS rate, 1-year PFS rate, and 2-year PFS rate for patients with advanced CRC}

Cluster analysis was performed for SUCRA values of ORR, DCR, 1-year OS rate, and 1-year PFS rate. The results illustrated that compared with other chemotherapy regimens, FOLFOX, FOLFIRI, and TOMOX had better short-term and long-term efficacies. The FOLFOX and FOLFIRI values were clustered, and the efficacy of FF and raltitrexed was poor for patients with advanced CRC (Figure 3).

\section{DISCUSSION}

This study conducted a network meta-analysis of 10 first-line chemotherapy regimens to compare the short-term and long-term efficacies in patients suffering from advanced CRC. The analysis results demonstrated that FOLFOX, FOLFIRI, and TOMOX achieved better outcomes in the treatment of advanced CRC when compared with FFG, FF, and IROX.
FOLFOX, FOLFIRI, and TOMOX had better shortterm and long- term efficacies. FOLFOX, FOLFIRI, and TOMOX had higher ORRs and 1-year PFS rates. Hideo et al. [32] demonstrated that the FOLFOX4 regimen shows good efficacy with an acceptable overall toxicity profile in a Japanese population. Iwamoto [33] reported that the FOLFIRI regimen as first-line treatment shows better response rate efficacy ( $41 \%)$, time to progression (6.7 months), and median survival time (17.4 months). Furthermore, FOLFIRI had better DCR and 2-year OS rate efficacies. Ludwig et al. [21] demonstrated that high-dose folinic acid/5-fluorouracil plus irinotecan shows superior activity, which appeared to have comparable clinical activity for ORR, PFS, and OS, which is consistent with our results. In addition, TOMOX had the highest SUCRA values for ORR, DCR, 1-year OS rate, and 2-year OS rate. TOMOX had a higher ORR. Martoni et al. [34] reported that the combination of raltitrexed and oxaliplatin is active in advanced CRC, which is consistent with our findings. Moreover, Sandro et al. [35] showed that TOMOX has better RR (45\%) and is active as a first-line chemotherapy regimen for advanced CRC. The chemotherapeutic mechanisms of oxaliplatin and irinotecan function by disrupting related pathways of epidermal growth factor receptor (EGFR) and vascular endothelial growth factor (VEGF) [36], which inhibits further proliferation and metastasis of tumors to achieve a meaningful efficacy. Oxaliplatin is a novel platinum derivative that suppresses DNA replication via the formation of DNA adducts, and it has activity in advanced tumor treatment both in combination and in monotherapy arms [37]. Raltitrexed 
is a specific inhibitor of thymidylate synthase (TS). Raltitrexed is polyglutamated via folylpolyglutamate synthase and enters cells through the reduced-folate carrier, which enhances intracellular retention and results in prolonged TS inhibition, DNA fragmentation, and cell death [20]. To some extent, the results of this study are reasonable and can provide support for selection of effective chemotherapy regimens in the treatment of advanced CRC. Additionally, FF and raltitrexed regimens showed relatively poor efficacy in the treatment of advanced CRC. FF and raltitrexed had lower ORRs and 1-year PFS rates. Twelves et al. [28] demonstrate that the ORR is lower for patients treated with FF than for patients receiving capecitabine (17.9\% vs. $26.6 \%)$.
When compared with FF, raltitrexed causes more thrombocytopenia and elevated liver transaminases [38].

The Bayesian network model is applied for an inconsistency test of direct and indirect evidence by using the node-splitting method. With this method, we can avoid the shortcomings of the traditional meta-analysis, which can only directly compare two different interventions to conduct direct and indirect comparisons of all the results, and thus achieve more complete analysis results [39]. Moreover, the test results showed all the direct and indirect evidence are consistent, suggesting that the results of this study are reliable. Still, due to the limited relative literatures, some included studies lacking sufficient comparisons may have a certain impact on the result. In
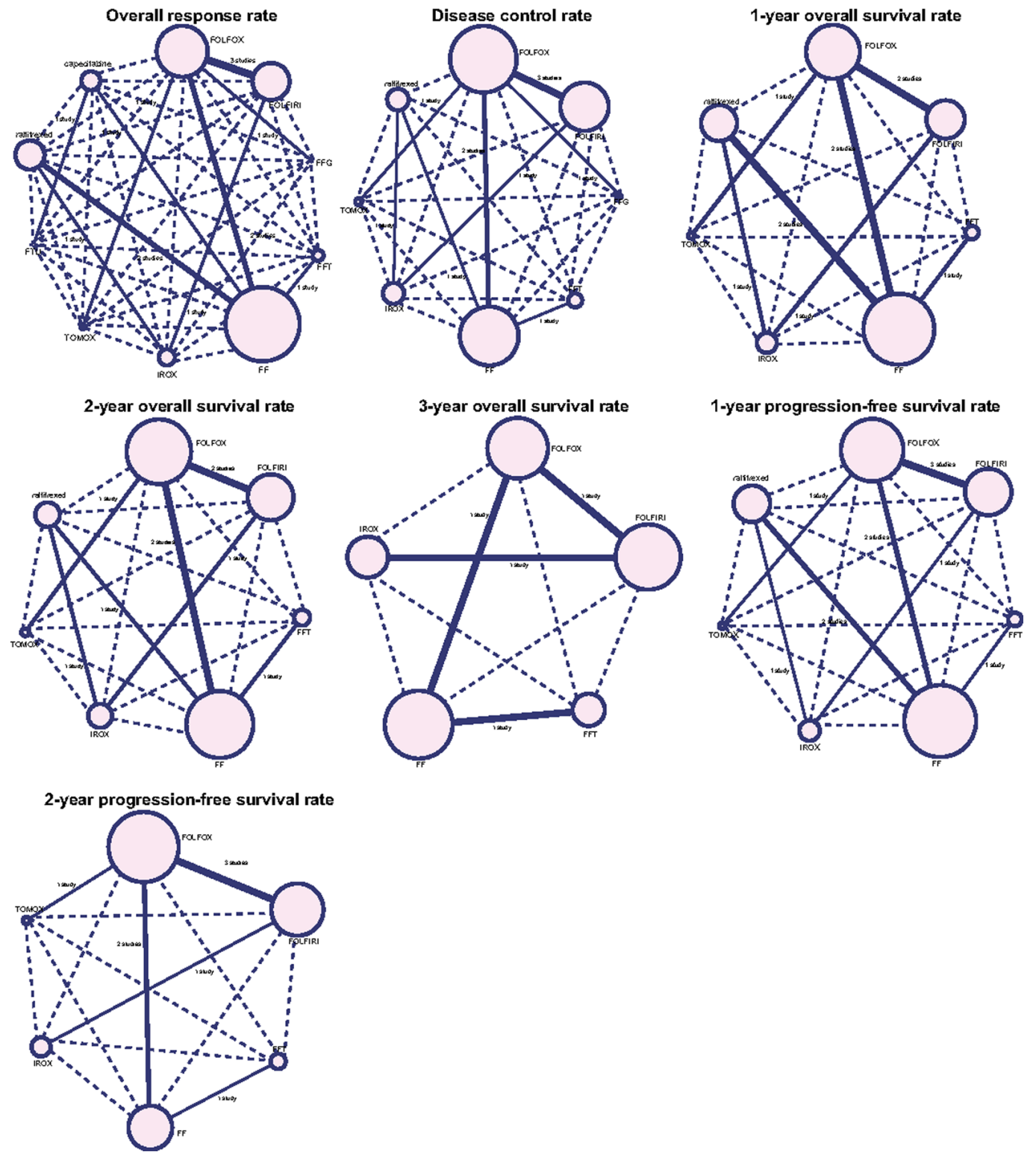

Figure 2: Network diagrams of ORR, DCR, 1-year OS rate, 2-year OS rate, 3-year OS rate, 1-year PFS rate, and 2-year PFS rate. Note: ORR, overall response rate; DCR, disease control rate; OS, overall survival; PFS, and progression-free survival $($ FOLFOX $=$ folinic acid +5 -fluorouracil + oxaliplatin, FOLFIRI $=$ folinic acid +5 -fluorouracil + irinotecan, $F F G=$ folinic acid + 5 -fluorouracil + gemcitabine, FFT $=$ folinic acid +5 -fluorouracil + trimetrexate, $F F=$ folinic acid +5 -fluorouracil, $I R O X=$ irinotecan + oxaliplatin, TOMOX = raltitrexed + oxaliplatin, and FTU $=$ folinic acid + tegafur-uracil). 
Table 2: OR values and $\boldsymbol{P}$ values of direct and indirect pairwise comparisons among five treatment modalities under five endpoint outcomes

\begin{tabular}{|c|c|c|c|c|c|c|c|c|c|c|c|c|c|c|c|}
\hline \multirow{2}{*}{$\begin{array}{c}\text { Pairwise } \\
\text { comparisons }\end{array}$} & \multicolumn{5}{|c|}{ Direct $O R$ values } & \multicolumn{5}{|c|}{ Indirect $O R$ values } & \multicolumn{5}{|c|}{$P$ values } \\
\hline & B vs. A & E vs. A & F vs. B & I vs. E & I vs. F & B vs. A & E vs. A & F vs. B & I vs. E & I vs. F & B vs. A & E vs. A & F vs. B & I vs. E & I vs. F \\
\hline ORR & 1.00 & 0.34 & 1.00 & 1.10 & 0.31 & 1.20 & 0.27 & 1.20 & 0.93 & 0.37 & 0.81 & 0.78 & 0.83 & 0.79 & 0.84 \\
\hline DCR & 1.10 & 0.52 & 0.50 & 0.97 & 0.36 & 2.80 & 0.21 & 1.20 & 0.39 & 0.93 & 0.20 & 0.22 & 0.24 & 0.21 & 0.21 \\
\hline $\begin{array}{c}\text { 1-year OS } \\
\text { rate }\end{array}$ & 0.97 & 0.81 & 0.72 & 0.87 & 0.94 & 1.10 & 0.72 & 0.81 & 0.79 & 1.00 & 0.88 & 0.87 & 0.85 & 0.85 & 0.89 \\
\hline $\begin{array}{l}\text { 2-year OS } \\
\text { rate }\end{array}$ & 1.20 & 0.83 & 0.68 & 0.81 & 0.77 & 1.30 & 0.72 & 0.77 & 0.74 & 0.87 & 0.86 & 0.83 & 0.82 & 0.87 & 0.85 \\
\hline $\begin{array}{c}\text { 1-year PFS } \\
\text { rate }\end{array}$ & 0.82 & 0.43 & 0.77 & 0.86 & 0.13 & 3.90 & 0.09 & 3.50 & 0.18 & 0.55 & 0.13 & 0.14 & 0.15 & 0.14 & 0.16 \\
\hline
\end{tabular}

Notes: $\mathrm{OR}=$ odds ratio; $\mathrm{ORR}=$ overall response rate; $\mathrm{DCR}=$ disease control rate; $\mathrm{OS}=$ overall survival; $\mathrm{PFS}=$ progression-free survival; $\mathrm{A}=\mathrm{FOLFOX}($ folinic acid +5 -fluorouracil + oxaliplatin);

$\mathrm{B}=$ FOLFIRI (folinic acid + 5-fluorouracil + irinotecan); E = FF (folinic acid + 5-fluorouracil); F = IROX (irinotecan + oxaliplatin); I = raltitrexed; J = capecitabine.

Table 3: SUCRA values of ten treatment modalities under seven endpoint outcomes

\begin{tabular}{|c|c|c|c|c|c|c|c|}
\hline \multirow[b]{2}{*}{ Treatments } & \multicolumn{7}{|c|}{ SUCRA values (\%) } \\
\hline & ORR & DCR & $\begin{array}{c}\text { 1-year OS } \\
\text { rate }\end{array}$ & $\begin{array}{c}\text { 2-year OS } \\
\text { rate }\end{array}$ & $\begin{array}{c}\text { 3-year } \\
\text { OS rate }\end{array}$ & 1-year PFS rate & $\begin{array}{c}\text { 2-year PFS } \\
\text { rate }\end{array}$ \\
\hline $\mathbf{A}$ & 75.5 & 74.9 & 74.3 & 64.4 & 75.2 & 84.4 & 76.0 \\
\hline B & 78.6 & 85.9 & 69.9 & 79.6 & 81.0 & 75.0 & 51.8 \\
\hline $\mathbf{C}$ & 30.9 & 52.6 & NR & NR & NR & NR & NR \\
\hline D & 41.1 & 30.1 & 65.9 & 47.4 & 41.0 & 30.3 & 67.8 \\
\hline $\mathbf{E}$ & 21.9 & 34.8 & 47.6 & 45.9 & 36.0 & 37.7 & 56.2 \\
\hline $\mathbf{F}$ & 77.6 & 55.6 & 34.4 & 44.4 & 67.0 & 70.0 & 33.3 \\
\hline G & 91.8 & 88.3 & 78.1 & 90.3 & NR & 80.9 & 65.3 \\
\hline $\mathbf{H}$ & 56.5 & NR & NR & NR & NR & NR & NR \\
\hline $\mathbf{I}$ & 26.5 & 27.3 & 30.9 & 27.7 & NR & 22.1 & NR \\
\hline $\mathbf{J}$ & 48.1 & NR & NR & NR & NR & NR & NR \\
\hline
\end{tabular}

Notes: SUCRA = surface under the cumulative ranking curves. ORR = overall response rate; DCR = disease control rate; OS = overall survival; PFS = progression-free survival; A = FOLFOX (folinic acid + 5-fluorouracil + oxaliplatin);

$\mathrm{B}=$ FOLFIRI (folinic acid + 5-fluorouracil + irinotecan) $\mathrm{C}=\mathrm{FFG}$ (folinic acid + 5-fluorouracil + gemcitabine) D $=$ FFT

(folinic acid +5 -fluorouracil + trimetrexate) $\mathrm{E}=\mathrm{FF}$ (folinic acid + 5-fluorouracil); F = IROX (irinotecan + oxaliplatin);

$\mathrm{G}=$ TOMOX (raltitrexed + oxaliplatin); H = FTU (folinic acid + tegafur-uracil); I = raltitrexed; $\mathrm{J}=$ capecitabine.

addition, the collected results from the included studies were uneven and the number of studies on some drugs was small. Such a situation causes inconsistency between pairwise meta-analysis conclusions and network metaanalysis conclusions. Because of the limitations in our study, we must collect more data from diagnostic studies to improve the results.

This study found that multi-drug regimens are superior to single-drug regimens for advanced CRC. Furthermore, FOLFOX, FOLFIRI, and TOMOX are much more beneficial for the treatment of advanced CRC.

\section{MATERIALS AND METHODS}

\section{Literature search}

This systematic review was performed according to Preferred Reporting Items for Systematic Reviews and Meta-Analyses (PRISMA) guidelines [40]. Electronic searches were performed in the Cochrane Library, PubMed and Embase databases from the inception to June 2017. We also searched for relevant studies that were missed in the initial electronic search by conducting a manual search of cross-references. The manual search was conducted using keywords combined with free words, mainly including chemotherapy, pharmacotherapy, oxaliplatin, fluorouracil, irinotecan, capecitabine, colorectal cancer etc.

\section{Inclusion and exclusion criteria}

The inclusion criteria were: (1) study design: randomized controlled trail (RCT); (2) chemotherapy regimens: folinic acid $+5-\mathrm{FU}+$ oxaliplatin (FOLFOX), folinic acid $+5-\mathrm{FU}+$ irinotecan (FOLFIRI), folinic acid +5 -FU + gemcitabine (FFG), folinic acid + 5-FU + trimetrexate (FFT), folinic acid +5 -FU (FF), irinotecan + oxaliplatin (IROX), raltitrexed + oxaliplatin (TOMOX), folinic acid + tegafur-uracil (FTU), raltitrexed, and capecitabine; (3) study subjects: patients with advanced CRC and at least one measurable lesion according to the Response Evaluation Criteria in Solid Tumors (RECIST) 
Version 1.0 [41]; (4) end outcomes: overall response rate (ORR), disease control rate (DCR), 1-year OS rate, 2-year OS rate, 3-year OS rate, 1-year progression-free survival (PFS) rate, or 2-year progression-free survival rate [42]. The exclusion criteria were: (1) studies without sufficient data, such as non-match researches; (2) non-RCTs; (3) duplicated publications; (4) conference reports, system assessments or abstracts; (5) studies investigating secondline chemotherapy regimens in the treatment of advanced CRC; (6) non-English literature; and (7) non-human studies.

\section{Data extraction and quality evaluation}

With uniform data collection sheets, two reviewers independently extracted information from the selected studies. Any disputes regarding the extraction of data were resolved by agreement among several investigators. Literature quality was assessed by over two reviewers in accordance with the Physiotherapy Evidence Database (PEDro) scale, which has 11 total points ( $\geq 4$ points, high quality; $<4$ points, low quality) [43].

\section{Statistical analysis}

We conducted pair-wise meta-analyses of direct evidence by using the fixed-effects model supplemented with R Version 3.2.1 software and the meta-analysis package. The pooled estimates of odds ratios (ORs) and $95 \%$ confidence intervals (CIs) of seven endpoint outcomes were shown. The Chi-squared test and the I-squared test were used to test heterogeneity among the studies [44]. R 3.2.1 was applied with the network package to a draw net-like relation graph, in which each node refers to one intervention, node size refers to sample size, and line thickness between nodes refers to the quantity of enrolled studies. A random-effects network meta-analysis was performed by application of the GEMTC package. Lu and Ades [45] described random-effects network metaanalysis models, with the relative effects (e.g., log-odds ratio) fitting a generalized linear model (GLM) under the Bayesian framework by linking to JAGS, OpenBUGS, or WinBUGS. We used the node-splitting method to estimate consistency between the direct evidence and indirect evidence. Based on the results, a consistency or

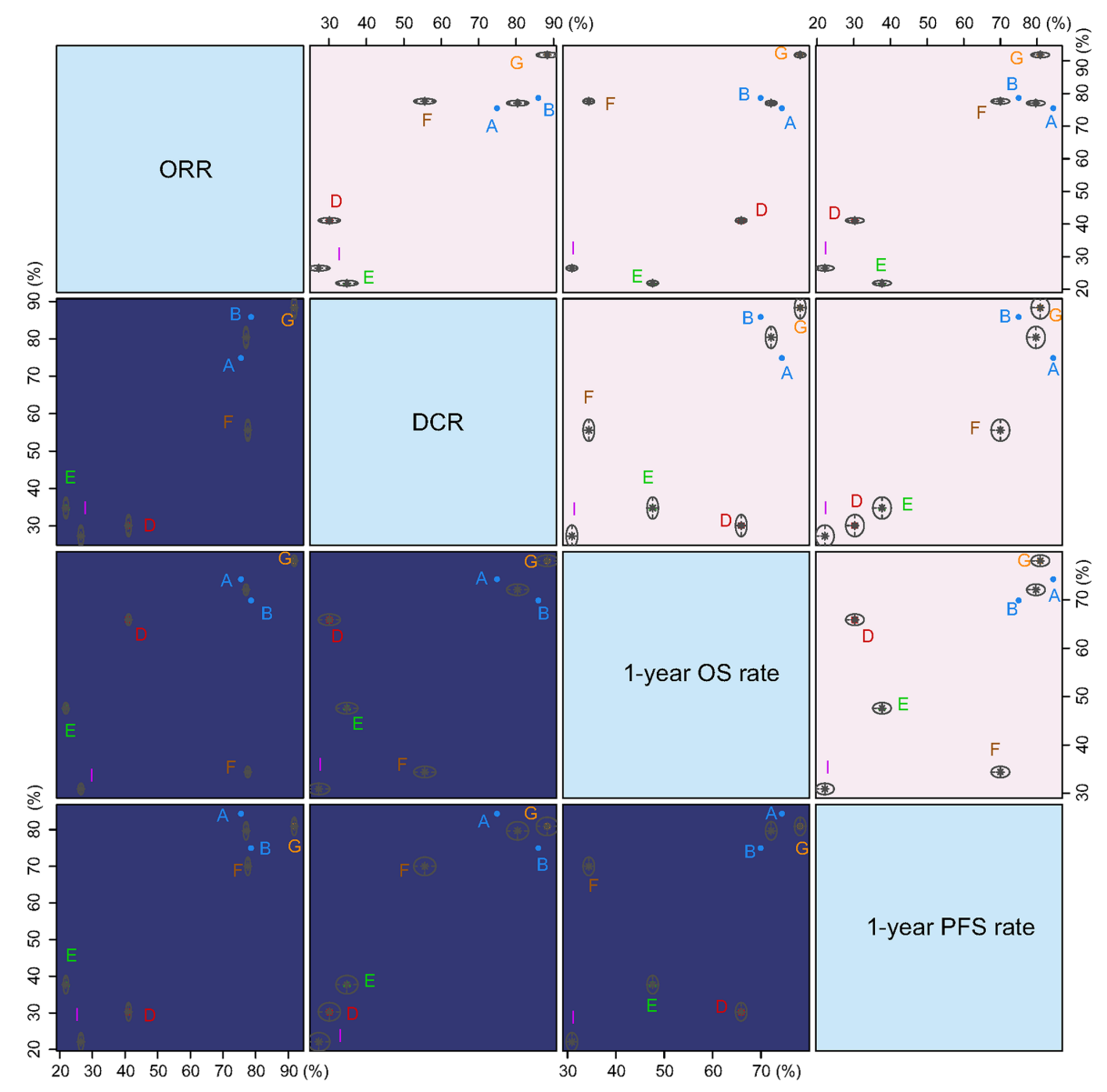

Figure 3: Cluster analysis diagrams of ORR, DCR, 1-year OS rate, and 1-year PFS rate. Note: ORR, overall response rate; DCR, disease control rate; OS, overall survival; and PFS, progression-free survival. (A) FOLFOX (folinic acid + 5-fluorouracil + oxaliplatin), (B) FOLFIRI (folinic acid + 5-fluorouracil + irinotecan), (C) FFG (folinic acid + 5-fluorouracil + gemcitabine), (D) FFT (folinic acid + 5-fluorouracil + trimetrexate), (E) FF (folinic acid + 5-fluorouracil), (F) IROX (irinotecan + oxaliplatin), (G) TOMOX (raltitrexed + oxaliplatin), (H) FTU (folinic acid + tegafur-uracil), (I) raltitrexed, and (J) capecitabine. 
an inconsistency model was selected. When the results of node-splitting methods were $P>0.05$, a consistency model was selected for the analysis [46]. To assist with the interpretation of ORs, we calculated the probability of each intervention that was the most effective treatment method based on a Bayesian approach using probability values summarized as surface under the cumulative ranking curves (SUCRA). That is, the larger the SUCRA value, the better the rank of the intervention [47, 48]. Cluster analyses were used to group the treatments on the basis of their similarity to primary and secondary outcomes [47]. All analyses were performed with R 3.2.1 software.

\section{ACKNOWLEDGMENTS AND FUNDING}

This work was supported by the Priority Academic Program Development of Jiangsu Higher Education Institutions (PAPD); the 2016 "333 Project" Award of Jiangsu Province, the 2013 "Qinglan Project" of the Young and Middle-aged Academic Leader of Jiangsu College and University, the National Natural Science Foundation of China $(81571055,81400902,81271225,31201039$, 81171012, and 30950031), the Major Fundamental Research Program of the Natural Science Foundation of the Jiangsu Higher Education Institutions of China (13KJA180001), and grants from the Cultivate National Science Fund for Distinguished Young Scholars of Jiangsu Normal University. We acknowledge the helpful comments on this paper received from our reviewers.

\section{CONFLICTS OF INTEREST}

There was no conflicts of interest existing in this paper.

\section{REFERENCES}

1. Zhu GQ, You J, Shi KQ, He SY, Wang LR, Chen YP, Braddock M, Zheng MH. Systematic review with network meta-analysis: adjuvant chemotherapy for resected colorectal liver metastases. Medicine (Baltimore). 2015; 94:e379.

2. Ferlay J, Soerjomataram I, Dikshit R, Eser S, Mathers C, Rebelo M, Parkin DM, Forman D, Bray F. Cancer incidence and mortality worldwide: sources, methods and major patterns in GLOBOCAN 2012. Int J Cancer. 2015; 136:E359-86.

3. Karsa LV, Lignini TA, Patnick J, Lambert R, Sauvaget C. The dimensions of the CRC problem. Best Pract Res Clin Gastroenterol. 2010; 24:381-96.

4. Grady WM, Markowitz SD. The molecular pathogenesis of colorectal cancer and its potential application to colorectal cancer screening. Dig Dis Sci. 2015; 60:762-72.

5. Kijima S, Sasaki T, Nagata K, Utano K, Lefor AT, Sugimoto H. Preoperative evaluation of colorectal cancer using CT colonography, MRI, and PET/CT. World J Gastroenterol. $2014 ; 20: 16964-75$.

6. Kim JB, Lee HS, Lee HJ, Kim J, Yang DH, Yu CS, Kim JC, Byeon JS. Long-Term Outcomes of Endoscopic Versus Surgical Resection of Superficial Submucosal Colorectal Cancer. Dig Dis Sci. 2015; 60:2785-92.

7. Hollande F, Pannequin J, Joubert D. The long road to colorectal cancer therapy: searching for the right signals. Drug Resist Updat. 2010; 13:44-56.

8. Longley DB, Harkin DP, Johnston PG. 5-fluorouracil: mechanisms of action and clinical strategies. Nat Rev Cancer. 2003; 3:330-8.

9. Twelves C, Wong A, Nowacki MP, Abt M, Burris H 3rd, Carrato A, Cassidy J, Cervantes A, Fagerberg J, Georgoulias V, Husseini F, Jodrell D, Koralewski P, et al. Capecitabine as adjuvant treatment for stage III colon cancer. N Engl J Med. 2005; 352: 2696-704.

10. Negrei C, Hudita A, Ginghina O, Galateanu B, Voicu SN, Stan M, Costache M, Fenga C, Drakoulis N, Tsatsakis AM. Colon Cancer Cells Gene Expression Signature As Response to 5- Fluorouracil, Oxaliplatin, and Folinic Acid Treatment. Front Pharmacol. 2016; 7:172.

11. Liu Y, Wu W, Hong W, Sun X, Wu J, Huang Q. Raltitrexedbased chemotherapy for advanced colorectal cancer. Clin Res Hepatol Gastroenterol. 2014; 38:219-25.

12. Terstriep S, Grothey A. First- and second-line therapy of metastatic colorectal cancer. Expert Rev Anticancer Ther. 2006; 6:921-30

13. Aitini E, Rossi A, Morselli P, Vivorio B, Bruschi A, Bottura C, Colombo GL. Economic comparison of capecitabine + oxaliplatin and 5-fluorouracil + oxaliplatin in the adjuvant treatment of colon cancer. Cancer Manag Res. 2012; 4:99-103.

14. Peinert S, Grothe W, Stein A, Muller LP, Ruessel J, Voigt W, Schmoll HJ, Arnold D. Safety and efficacy of weekly 5-fluorouracil/folinic acid/oxaliplatin/irinotecan in the first-line treatment of gastrointestinal cancer. Ther Adv Med Oncol. 2010; 2:161-74.

15. Gustavsson B, Carlsson G, Machover D, Petrelli N, Roth A, Schmoll HJ, Tveit KM, Gibson F. A review of the evolution of systemic chemotherapy in the management of colorectal cancer. Clin Colorectal Cancer. 2015; 14:1-10.

16. Jansen JP, Fleurence R, Devine B, Itzler R, Barrett A, Hawkins N, Lee K, Boersma C, Annemans L, Cappelleri JC. Interpreting indirect treatment comparisons and network meta-analysis for health-care decision making: report of the ISPOR Task Force on Indirect Treatment Comparisons Good Research Practices: part 1. Value Health. 2011; 14:417-28.

17. Benson AB 3rd, Venook AP, Cederquist L, Chan E, Chen YJ, Cooper HS, Deming D, Engstrom PF, Enzinger PC, Fichera A, Grem JL, Grothey A, Hochster HS, et al. Colon Cancer, Version 1.2017, NCCN Clinical Practice Guidelines in Oncology. J Natl Compr Canc Netw. 2017; 15:370-98. 
18. Kroep JR, van Werkhoven E, Polee M, van Groeningen CJ, Beeker A, Erdkamp F, Weijl N, van Bochove A, Erjavec Z, Kapiteijn E, Stiggelbout AM, Nortier HW, Gelderblom H. Randomised study of tegafur-uracil plus leucovorin versus capecitabine as first-line therapy in elderly patients with advanced colorectal cancer--TLC study. J Geriatr Oncol. 2015; 6:307-15.

19. Madajewicz S, Waterhouse DM, Ritch PS, Khan MQ, Higby DJ, Leichman CG, Malik SK, Hentschel P, Gill JF, Zhao L, Nicol SJ. Multicenter, randomized phase II trial of bevacizumab plus folinic acid, fluorouracil, gemcitabine (FFG) versus bevacizumab plus folinic acid, fluorouracil, oxaliplatin (FOLFOX4) as first-line therapy for patients with advanced colorectal cancer. Invest New Drugs. 2012; 30:772-8.

20. Gravalos C, Salut A, Garcia-Giron C, Garcia-Carbonero R, Leon AI, Sevilla I, Maurel J, Esteban B, Garcia-Rico E, Murias A, Cortes-Funes H. A randomized phase II study to compare oxaliplatin plus 5-fluorouracil and leucovorin (FOLFOX4) versus oxaliplatin plus raltitrexed (TOMOX) as first-line chemotherapy for advanced colorectal cancer. Clin Transl Oncol. 2012; 14:606-12.

21. Fischer von Weikersthal L, Schalhorn A, Stauch M, Quietzsch D, Maubach PA, Lambertz H, Oruzio D, Schlag R, Weigang-Kohler K, Vehling-Kaiser U, Schulze M, Truckenbrodt J, Goebeler M, et al. Phase III trial of irinotecan plus infusional 5-fluorouracil/folinic acid versus irinotecan plus oxaliplatin as first-line treatment of advanced colorectal cancer. Eur J Cancer. 2011; 47:206-14.

22. Hospers GA, Schaapveld M, Nortier JW, Wils J, van Bochove A, de Jong RS, Creemers GJ, Erjavec Z, de Gooyer DJ, Slee PH, Gerrits CJ, Smit JM, Mulder NH. Randomised Phase III study of biweekly 24-h infusion of high-dose 5FU with folinic acid and oxaliplatin versus monthly plus 5-FU/folinic acid in first-line treatment of advanced colorectal cancer. Ann Oncol. 2006; 17:443-9.

23. Kalofonos HP, Aravantinos G, Kosmidis P, Papakostas P, Economopoulos T, Dimopoulos M, Skarlos D, Bamias A, Pectasides D, Chalkidou S, Karina M, Koutras A, Samantas E, et al. Irinotecan or oxaliplatin combined with leucovorin and 5-fluorouracil as first-line treatment in advanced colorectal cancer: a multicenter, randomized, phase II study. Ann Oncol. 2005; 16:869-77.

24. Colucci G, Gebbia V, Paoletti G, Giuliani F, Caruso M, Gebbia N, Cartenì G, Agostara B, Pezzella G, Manzione L, Borsellino N, Misino A, Romito S, et al, and Gruppo Oncologico Dell'Italia Meridionale. Phase III randomized trial of FOLFIRI versus FOLFOX4 in the treatment of advanced colorectal cancer: a multicenter study of the Gruppo Oncologico Dell'Italia Meridionale. J Clin Oncol. 2005; 23:4866-75.

25. Tournigand C, Andre T, Achille E, Lledo G, Flesh M, MeryMignard D, Quinaux E, Couteau C, Buyse M, Ganem G, Landi B, Colin P, Louvet C, et al. FOLFIRI followed by FOLFOX6 or the reverse sequence in advanced colorectal cancer: a randomized GERCOR study. J Clin Oncol. 2004; 22:229-37.

26. Scheithauer W, Kornek GV, Raderer M, Ulrich-Pur H, Fiebiger W, Gedlicka C, Schull B, Brugger S, Schneeweiss B, Lang F, Lenauer A, Depisch D. Randomized multicenter phase II trial of oxaliplatin plus irinotecan versus raltitrexed as first-line treatment in advanced colorectal cancer. J Clin Oncol. 2002; 20:165-72.

27. Blanke CD, Shultz J, Cox J, Modiano M, Isaacs R, Kasimis B, Schilsky R, Fleagle J, Moore M, Kemeny N, Carlin D, Hammershaimb L, Haller D, et al. A double-blind placebocontrolled randomized phase III trial of 5-fluorouracil and leucovorin, plus or minus trimetrexate, in previously untreated patients with advanced colorectal cancer. Ann Oncol. 2002; 13:87-91.

28. Twelves C, Boyer M, Findlay M, Cassidy J, Weitzel C, Barker C, Osterwalder B, Jamieson C, Hieke K, and Xeloda Colorectal Cancer Study Group. Capecitabine (Xeloda) improves medical resource use compared with 5-fluorouracil plus leucovorin in a phase III trial conducted in patients with advanced colorectal carcinoma. Eur J Cancer. 2001; 37:597-604.

29. de Gramont A, Figer A, Seymour M, Homerin M, Hmissi A, Cassidy J, Boni C, Cortes-Funes H, Cervantes A, Freyer G, Papamichael D, Le Bail N, Louvet C, et al. Leucovorin and fluorouracil with or without oxaliplatin as first-line treatment in advanced colorectal cancer. J Clin Oncol. 2000; 18:2938-47.

30. Cocconi G, Cunningham D, Van Cutsem E, Francois E, Gustavsson B, van Hazel G, Kerr D, Possinger K, Hietschold SM, and Tomudex Colorectal Cancer Study Group. Open, randomized, multicenter trial of raltitrexed versus fluorouracil plus high-dose leucovorin in patients with advanced colorectal cancer. J Clin Oncol. 1998; 16:2943-52.

31. Cunningham D, Zalcberg JR, Rath U, Oliver I, van Cutsem E, Svensson C, Seitz JF, Harper P, Kerr D, Perez-Manga G. Final results of a randomised trial comparing 'Tomudex' (raltitrexed) with 5-fluorouracil plus leucovorin in advanced colorectal cancer. "Tomudex" Colorectal Cancer Study Group. Ann Oncol. 1996; 7:961-5.

32. Park YH, Kang SH, Kim SU, Kim DY, Park JY, Ahn SH, Han KH, Chon CY. [A case of hepaticoduodenal fistula development after transarterial chemoembolization in patient with hepatocellular carcinoma]. [Article in Korean]. Korean J Gastroenterol. 2011; 58:149-52.

33. Iwamoto S, Hazama S, Kato T, Miyake Y, Fukunaga M, Matsuda C, Bando H, Sakamoto J, Oba K, Mishima H. Multicenter phase II study of second-line cetuximab plus folinic acid/5-fluorouracil/irinotecan (FOLFIRI) in KRAS wild-type metastatic colorectal cancer: the FLIER study. Anticancer Res. 2014; 34:1967-73.

34. Martoni A, Mini E, Pinto C, Gentile AL, Nobili S, Dentico P, Marino A, Scicolone S, Angelelli B, Mazzei T. Oxaliplatin plus raltitrexed in the treatment of patients with 
advanced colorectal cancer: a phase II study. Anticancer Res. 2003; 23:687-91.

35. Barni S, Ghidini A, Coinu A, Borgonovo K, Petrelli F. A systematic review of raltitrexed-based first-line chemotherapy in advanced colorectal cancer. Anticancer Drugs. 2014; 25:1122-8.

36. Nielsen DL, Palshof JA, Larsen FO, Jensen BV, Pfeiffer P. A systematic review of salvage therapy to patients with metastatic colorectal cancer previously treated with fluorouracil, oxaliplatin and irinotecan $+/$ - targeted therapy. Cancer Treat Rev. 2014; 40:701-15.

37. Fizazi K, Doubre H, Le Chevalier T, Riviere A, Viala J, Daniel C, Robert L, Barthelemy P, Fandi A, Ruffie P. Combination of raltitrexed and oxaliplatin is an active regimen in malignant mesothelioma: results of a phase II study. J Clin Oncol. 2003; 21:349-54.

38. Ransom D, Wilson K, Fournier M, Simes RJ, Gebski V, Yip D, Tebbutt N, Karapetis CS, Ferry D, Gordon S, Price TJ. Final results of Australasian Gastrointestinal Trials Group ARCTIC study: an audit of raltitrexed for patients with cardiac toxicity induced by fluoropyrimidines. Ann Oncol. 2014; 25:117-21.

39. Yan M, Kumachev A, Siu LL, Chan KK. Chemoradiotherapy regimens for locoregionally advanced nasopharyngeal carcinoma: A Bayesian network metaanalysis. Eur J Cancer. 2015; 51:1570-9.

40. Moher D, Liberati A, Tetzlaff J, Altman DG, and PRISMA Group. Preferred reporting items for systematic reviews and meta-analyses: the PRISMA statement. Int J Surg. 2010; 8:336-41.

41. Yamazaki K, Kuwano H, Ojima H, Otsuji T, Kato T, Shimada K, Hyodo I, Nishina T, Shirao K, Esaki T, Ohishi T, Denda T, Takeuchi M, et al. A randomized phase II study of combination therapy with S-1, oral leucovorin, and oxaliplatin (SOL) and mFOLFOX6 in patients with previously untreated metastatic colorectal cancer. Cancer Chemother Pharmacol. 2015; 75:569-77.
42. Ronot M, Bouattour M, Wassermann J, Bruno O, Dreyer C, Larroque B, Castera L, Vilgrain V, Belghiti J, Raymond E, Faivre S. Alternative Response Criteria (Choi, European association for the study of the liver, and modified Response Evaluation Criteria in Solid Tumors [RECIST]) Versus RECIST 1.1 in patients with advanced hepatocellular carcinoma treated with sorafenib. Oncologist. 2014; 19:394-402.

43. Maher CG, Sherrington C, Herbert RD, Moseley AM, Elkins M. Reliability of the PEDro scale for rating quality of randomized controlled trials. Phys Ther. 2003; 83:713-21.

44. Chen LX, Li YL, Ning GZ, Li Y, Wu QL, Guo JX, Shi HY, Wang XB, Zhou Y, Feng SQ. Comparative efficacy and tolerability of three treatments in old people with osteoporotic vertebral compression fracture: a network meta-analysis and systematic review. PLoS One. 2015; 10:e0123153.

45. $\mathrm{Lu} \mathrm{G}$, Ades AE. Combination of direct and indirect evidence in mixed treatment comparisons. Stat Med. 2004; 23:3105-24.

46. Zhu GQ, Shi KQ, Huang S, Wang LR, Lin YQ, Huang GQ, Chen YP, Braddock M, Zheng MH. Systematic review with network meta-analysis: the comparative effectiveness and safety of interventions in patients with overt hepatic encephalopathy. Aliment Pharmacol Ther. 2015; 41:624-35.

47. Chaimani A, Higgins JP, Mavridis D, Spyridonos P, Salanti G. Graphical tools for network meta-analysis in STATA. PLoS One. 2013; 8:e76654.

48. Salanti G, Ades AE, Ioannidis JP. Graphical methods and numerical summaries for presenting results from multipletreatment meta-analysis: an overview and tutorial. J Clin Epidemiol. 2011; 64:163-71. 